\title{
The current approach to research and design of the artificial hip prosthesis: a review
}

\author{
K. Colic ${ }^{*}$ and A.Sedmak ${ }^{2}$ \\ ${ }^{1}$ University of Belgrade, Innovation Center, Faculty of Mechanical Engineering, Kraljice Marije 16, 11000 Belgrade, Serbia \\ ${ }^{2}$ University of Belgrade, Faculty of Mechanical Engineering, Kraljice Marije 16, 11000 Belgrade, Serbia
}

\begin{abstract}
One of the most successful techniques in restoration of degenerated joint functions is total hip replacement. This surgical approach includes removal of diseased cartilage and bone parts, and replacement by the corresponding joint prostheses. By using metal alloys, high quality plastic and polymer materials, orthopedic surgeons can reconstruct hip fractures, or replace a painful, dysfunctional joint with highly functional, long-lasting prostheses, enabling hundreds of thousands of people to live a more fulfilling and active life. However, most of these implants only last for 10-15 years, and one of the most common problems for both patients and doctors is implant failure. Observed in long-term, implant loosening is the main cause of failure. Occasionally, dislocation or bending of implants may occur. Fatigue fracture and wear were identified as the main problems related to loosening of implants, stress shielding, and final implant failure. There are several factors which contribute to implant integrity, including material and design, implant positioning, cementing technique and patient characteristics. To improve integrity and life of hip implant by using finite element analysis, two major factor should be considered, design and biomaterial. By using this method there are various parameters that should be define, including complex geometry of the bone and an implant, biomaterial properties, and specifics boundary conditions, i.e. contact between the hip prosthesis and the bone depending on fixation method. In orthopedic biomechanics finite element method was first used for the purpose of determining the stresses in human bones. Since then, this method has been more and more frequently applied in determining of stress state in bones and prostheses, as well as fracture fixation devices, including hip implants. This paper presents a review study of factors influencing design process and structural integrity of the hip implant.
\end{abstract}

\section{Introduction}

Total hip replacement (Figure 1), [1,2], is an effective treatment for severe forms of osteoarthritis, invalidating effects of rheumatoid arthritis, birth defects, and some sort of post-traumatic states. An increasing number of the elderly people, combined with longer life expectancy, have led to the need for better and longer-lasting orthopedic implants.

Since the current life span of implants is between 10-15 years, this can lead to four revisions during the life of the patient. An important factor during these revisions is the amount of bone remaining after surgery, which should carry the new implant, whereas the amount of residual bone largely depends on the type of implant used [3]. Another encountered problem is that when the bone is damaged during implant fixation, it regenerates naturally, but not in its original form. Bone remodeling presents a problem for good implant fixation within the acetabular cup. This condition can cause e.g. the head of the implant to fall out of place, or other cases of displacement of the implant from its designated position $[4,5]$. The wear of the implant presents a problem as well [6-8]. In contrast to human bones, which can be biologically regenerated, the implant cannot repair itself or grow.

\section{Problems that lead to the need for hip surgery}

The hip joint allows the articulation between the femur and acetabulum of the pelvis. From a medical point of view, the hip is one of the major joints in the body. Walking depends on a healthy, pain-free hip. Osteoarthritis represents the primary reason for a large number of total hip replacements. Osteoarthritis of femoral neck leads to hundreds of thousands of hip fractures per year, of which almost all require surgical treatment using a metal part for fixation and implant applications $[9,10]$. To understand the mechanics of the hip and the demands placed before implants that correct its problems, it is important to know the forces acting on the hip during the gait cycle.

Several millions of people worldwide suffer hip fractures each year, with the risk of fracture in women $40 \%$, men: $13 \%$ [10-13]. Osteoporosis is a decrease in bone mass often occurring with advancing of age, and the risk of fractures in people with osteoporosis is extremely high. A wide range of factors can affect the risk of hip fracture, and some of them include gender, age, and degree of osteoporosis, body weight and height [11-17]. Hip fracture occurs as a result of extreme force, with the most common cause of collision with the body surface. Various forms and degrees of hip fractures are the result of complex deformation occurring in direct collision with the hip pad. As there is a different distribution of internal stresses in the femur, very different types of hip fracture may occur.

One of the most common is the fracture of the femoral neck, which is considered an intracapsular fracture. In terms of extracapsular hip fractures, we can identify two types of fractures, intertrochanteric and sub-trochanteric fractures. In the case where it is necessary to remove the head and the neck of the femur, partial or total arthroplasty is used

Correspondence to: K. Colic, University of Belgrade, Innovation Center, Faculty of Mechanical Engineering, Kraljice Marije 16, 11000 Belgrade, Serbia, E-mail: kbojic@mas.bg.ac.rs

Key words: total hip replacement, orthopedic implant design, hip implant biomaterials, FEM in biomedicine, structural integrity

Received: November 15, 2016; Accepted: December 23, 2016; Published: December 27, 2016 
as a selected surgical procedure. Total hip prosthesis is applied when the clinical picture implies the existence of osteoarthritis, rheumatoid arthritis or other pathological conditions.

Total hip arthroplasty (THA) is a widely-used strategy of restoration of normal function of the hip joint, which was disrupted due to fractures or diseases $[1,2,18-23]$.

\section{Factors influencing hip prosthetic integrity and life}

The forces acting on the prosthesis, [24-28] caused by human activity are the result of dynamic stress that varies in time and leads to mechanical fatigue of the implant. It is therefore essential to ensure that the prosthesis does not fail due to fatigue, Figure 2.

Although fatigue fracture incidence in hip prostheses has been significantly reduced over the past decades, it still presents a problem [29-32]. Long-term performance and success of the cemented total hip arthroplasty are associated with connection of prosthesis to the bone

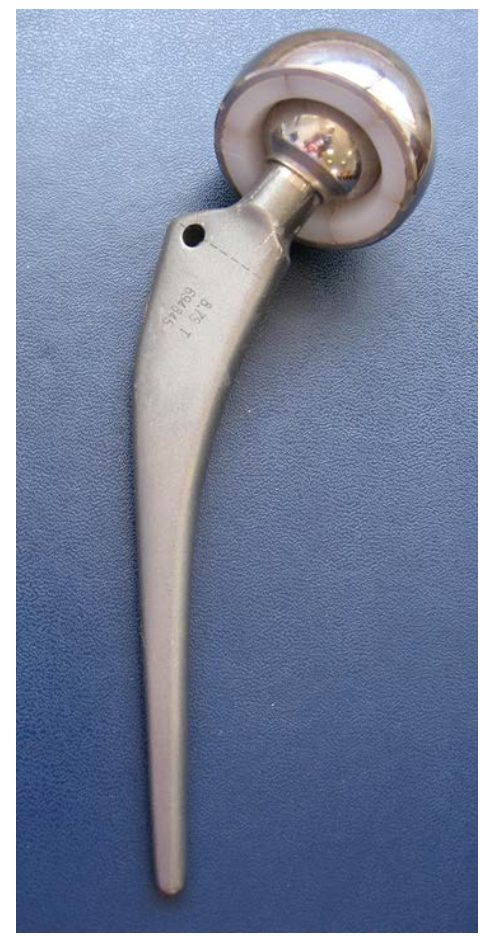

Figure 1. The total hip replacement implant

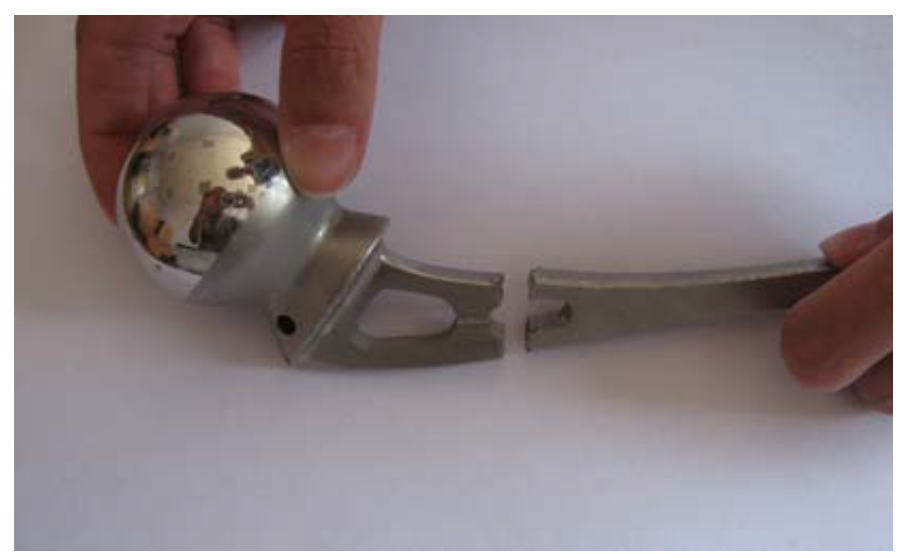

Figure 2. Failure of the hip prosthesis.
$[2,33,34]$. Failure of cement-metal interface, caused by detachment of the stem-cement and cement fracture may initiate implant loosening in the long term, $[4,33-36]$ according to the scenario of failure due to accumulation of damage to the stem-cement prostheses. If the design of the stem causes the formation of increased stress in the areas of fixation of the prosthesis, it is likely that ether a short-term fracture, or a long-term prosthesis fatigue will occur.

Long-term failure of cement implant is often related to particle breakage and wear and tear caused by the fragmentation of the cement due to the high stresses and accelerated micro-movements at the contact area [35-37]. It is believed that the presence of a large amount of particles causes the periprosthetic osteolysis, [38], most probably due to the migration of particles of a compound along the bone-implant contact area. The reliability of attachment of the orthopedic implant is therefore is influenced by many factors, such as the bone quality and design of the implant and of the interface.

Femoral bone is the largest and strongest bone in the human body, located between the hip and the knee. From the mechanical standpoint, the bone can be viewed as relatively sturdy and lightweight composite material formed mainly of collagen and hydroxyapatite $[39,40]$.

Femoral bone has a relatively high compressive strength of about $170 \mathrm{MPa}$, which means it has good resistance to compression force, but not as good resistance to tensile and torsional forces. The modulus of elasticity of bone varies between 0.76 and $19.6 \mathrm{GPa}$, [39,40]. Although the bone is predominantly brittle material, it has a significant degree of elasticity, which is provided by collagen. Characteristics of the femoral bone vary depending on gender, age and level of activity of the individual.

Postoperative infection is one of the worst outcomes of surgery, [41-43]. Factors that influence the occurrence of infection after total hip replacement are the presence of a large amount of foreign material, hematoma formation making its removal more difficult, due to insufficient mobility of the joint. In such cases, it is necessary to remove the implant and the necrotic soft tissue and bone, with the appropriate treatment.

Besides infection, aseptic loosening is one of the major postoperative problems that may be caused by: mechanical failure of bone cement or even implants, the appearance of wear particles generated in the region of the interface, and the relative movement of the interface initiating stress shielding in the bone $[35,37,44,45]$. Each of these phenomena may initiate an inconvenient biological response, resulting in bone resorption and implant loosening.

\section{Hip implant biomaterial properties}

Since the main function of the long bones of the lower body is providing support for the transfer of loads, it is reasonable to expect that the initial materials introduced to replace the joints, such as artificial hips, were metals. Of course, their stiffness and strength considerably exceed bone parameters, as shown in Table $1[34,39,46-$ 48]. Three commonly used alloys in making hip implants are stainless steels, titanium alloys and Co-Cr alloys. [39,46] The mechanical properties of stainless steel have recently been substantially enhanced, and it represents a good alternative for older patients with lower levels of physical activity, lifetime expectancy or limited financial resources $[39,46,47]$. Cobalt-based alloys are resistant to corrosion, fatigue, wear and breakage of the alloy of iron, but their modulus of elasticity is higher than that of other biomaterials. Titanium alloys, particularly $\mathrm{Ti}-6 \mathrm{Al}-4 \mathrm{~V}$ and $\mathrm{Ti}-6 \mathrm{Al} 7 \mathrm{Nb}$, are currently the most suitable materials 
Table 1. Mechanical properties of hip implant biomaterials and tissues.

\begin{tabular}{|l|c|c|c|}
\hline Tissue/Biomaterial & $\begin{array}{c}\text { Elastic } \\
\text { modulus (GPa) }\end{array}$ & $\begin{array}{c}\text { Yield strenght } \\
\text { (GPa) }\end{array}$ & $\begin{array}{c}\text { Tensile } \\
\text { strength (GPa) }\end{array}$ \\
\hline Cortical Bone & & & \\
\hline (moist at low stress) & 15 & 0.03 & 0.07 \\
\hline (moist at high stress) & 30 & 0.07 & 0.15 \\
\hline Cartilage & $\begin{array}{c}\text { Strongly } \\
\text { viscoelastic }\end{array}$ & - & $0.007-0.015$ \\
\hline $316 \mathrm{~L}$ stainless steel & 210 & $0.24(0.80)$ & $0.60(1.0)$ \\
\hline Co-Cr (cast) & 225 & 0.525 & 0.735 \\
\hline Ti & & & \\
\hline $0 \%$ porosity & 110 & & 0.40 \\
\hline $40 \%$ porosity & 24 & & 0.076 \\
\hline Ti-6Al-4V & 120 & 0.830 & 0.9 \\
\hline $\mathrm{Al}_{2} \mathrm{O}_{3}$ & 350 & - & $1-10$ \\
\hline PMMA & 3.0 & - & $0.035-0.05$ \\
\hline UHMWPE & $0.6-1.8$ & - & $0.023-0.04$ \\
\hline
\end{tabular}

for the prosthesis joints, and are registered in the ASTM standard as biomaterials $[39,46]$.

Under normal conditions, body fluids, such as tissue fluids, lymph and blood, represent $0.9 \%$ saline solutions containing amino acids and proteins, but also solid components, such as traveling cells (leukocytes and macrophages) and blood particles (cells, platelets and erythrocytes). Described biological environment of the human body is extremely corrosive for metallic materials $[39,47,49]$.

The prosthesis used for hip replacement is comprised of a femur and acetabular components, and the femur base can be divided into the head, the neck and the body. In case of total hip replacement, the head is most commonly made of a cobalt-chrome alloy, alumina or zirconium, whereas the stem component is made of titanium alloy or CoCr-alloy, wherein steel $316 \mathrm{~L}$ was used in the past. Sliding surfaces are often made of cobalt-chrome alloys and ultra-high-molecular-weight polyethylene (UHMWPE), since such combination can achieve properties similar to low friction sliding surfaces. Polyethylene also possesses moderate plasticity, which allows it to deform, and thus create a suitable sliding surface in contact with the CoCr-alloy.

\section{The current approach to research and design of the implant}

The successful wide application of artificial hip prosthesis, which has progressed over the last few decades, represents the result of the scientific and technological development in orthopedic surgery and bioengineering, and in particular the synergy of medicine, biomaterials and biomechanics, Figure 3. It should be noted that the widespread use began around 1960 by introducing two invention of Sir John Charnley [39]. This system has seen many variations over the years, but it is still a significant factor in the modern joint replacement surgery.

Today, a wide range of total hip prosthesis designs, differing in geometric configurations and features, is available, for example two different designs are shown on Figure 4. Surgeons now have the ability to closely mimic the original geometry of the hip using the whole range of different stem lengths, for both primary and highly complicated revisions and operations [50-56]. Progress in the field of chemistry and application of bone cement has led to uniform, reliable implantation. Biomaterial research has led to the emergence of new, stronger components more resistant to fatigue [57-61]. Although all elements of design and manufacturing of implants are improved, long-term stability of the implant remains one of the biggest problems.

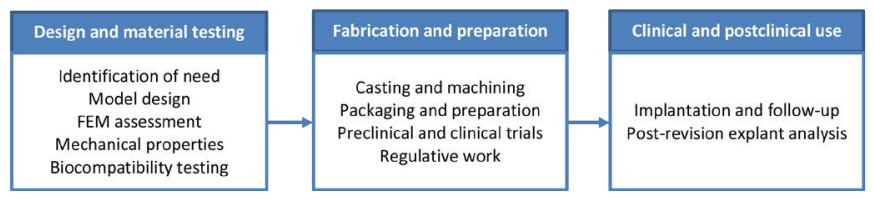

Figure 3. The modern approach to the design, fabrication and clinical use of the hip prosthesis

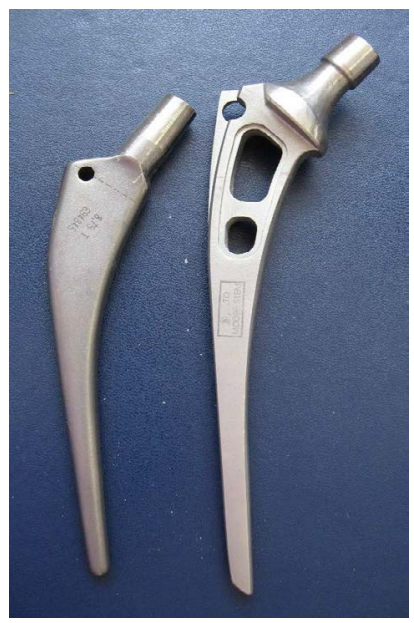

Figure 4. Different design examples of two cement prostheses.

Usually two types of total hip replacement are used. Depending on the type of interface with the carrier-bone, prosthesis can be either cement using bone cement to fix the prosthesis to the bone, or cementless, when the implant is placed directly into the bone cavity, followed by the reaction of bone known as osseointegration, which finally stabilizes the implant.

In the sense of implanting and manufacturing, there are currently two types of prostheses, monolithic (i.e. made from a single part), and modular (i.e., prostheses made of two or more parts). Modular components are assembled during the surgery itself, thus enabling the adjusting of implants intra-surgically and during future surgical revisions. This is a big advantage, in a sense that only the parts of the prosthesis where failure occurred can be replaced: for example, it is possible to replace worn-out polyethylene load bearing surfaces with new ones without removing the metal part of the prosthesis from the bone. However, the advantage of monolithic components, apart from the price, is the fact that they are less prone to corrosion and loosening.

Inasmuch the hip prosthesis is highly successful with the elderly, it is much less successful with younger people, since they apply greater and more frequent loads onto their joints in comparison [62-64]. Such prostheses are therefore more prone to failure, which leads to an increased number of early revision surgeries.

Therefore, careful evaluations of the biomaterial properties and hip prosthesis geometry must be carried out during preclinical tests to ascertain whether new designs can guarantee the mechanical resistance to the physiological load [29,65-67].

In order to understand the mechanisms of clinical fracture of implants, it is necessary to understand the following: the forces that act on the hip, stresses generated within the bone and the material implant, their wear effects, damage accumulation, and bone remodeling. Knowledge of biomechanics of the hip is important in determining 
fracture scenarios which is necessary for effective preclinical testing, Figure 5 [29].

An alternative approach would be the use of finite element method (FEM) to obtain a preliminary overview of the expected mechanical properties of candidate designs, Figure 6 [68]. This does not mean that the preclinical testing can be eliminated, but that this approach presents a swift way to detect design with potentially poor performance.

Even though it is approximate, FEM is rather common in biomedicine, since obtaining the exact solution is not possible due to complex geometry, material properties and specificity of boundary conditions [68-73]. Due to this, this method became a widely-used tool in orthopedic biomechanics, as a computational method suitable for determining of stresses and strain in any given point within a structure with arbitrary geometry and material complexity, given example in Figure 7 [69]. Finite element method relies on precise constitutive representation of material properties (such as elastic coefficients of a generalized Hooke's Law), geometry data, loading properties, boundary conditions and conditions at the joint.

In orthopedics, three-dimensional models are most frequently

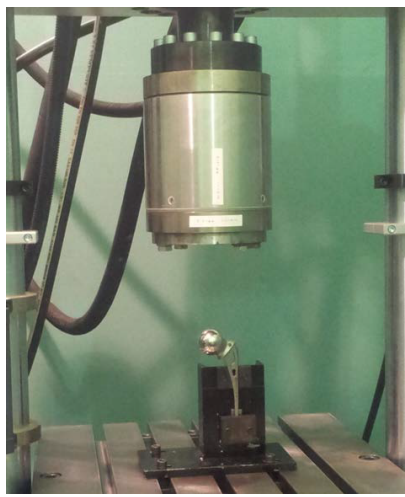

Figure 5. An example of hip implant fracture behavior experimental analysis [29].

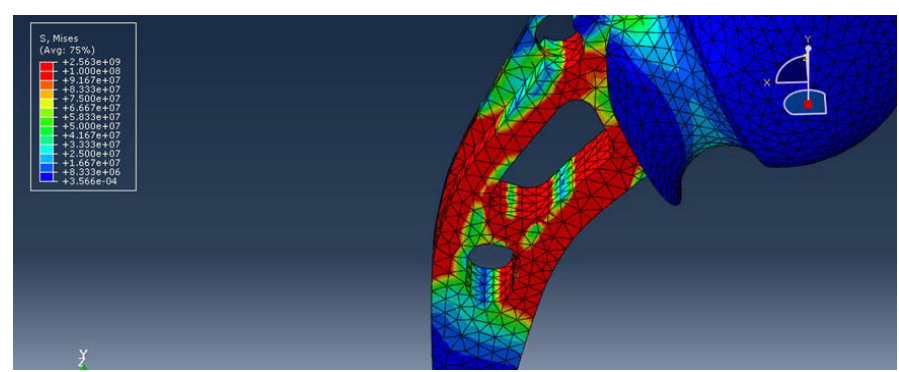

Figure 6. An example of FEM model for the hip implant fracture behavior numerical analysis [68].

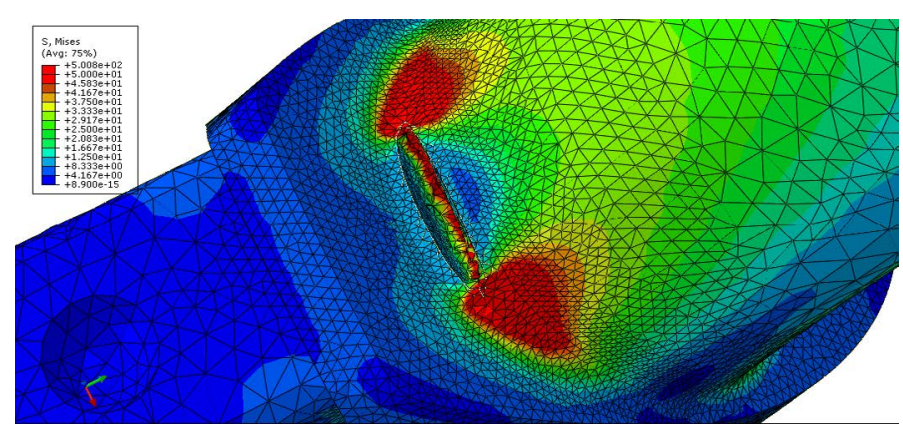

Figure 7. X-FEM model for the hip implant crack propagation numerical analysis [69]. used, however in some cases two-dimensional models can be used for simplified analysis. Table 2 presents some advantages of using finite element method, as well as factors that is not possible or is very difficult to include into numerical modeling of an implant integrity.

In order to develop a FEM model, the shape of bone or implant being analyzed is divided into small elements. For three-dimensional analysis, elementary volumes with certain geometry are used (such as bricks), and for two-dimensional analysis, elementary surfaces with specific geometry (e.g. triangles or rectangles). Every element has its nodes, usually located at the tips of the element. In each node point, three (or two in case of two-dimensional analysis) displacement component are determined along with three (two for 2D analysis) force components.

FEM became a powerful and reliable numerical tool for analysis of structures subjected to different types of load in cases where solving of these problems was too complex for exclusively analytical methods. Today there are some new analytical models as well, to more accurately represent hip implant integrity problems, i.e. more realistic wear simulation models [74]. There is some state of the art technics as well, so it is possible to simulate exact geometry of the hip, i.e. by using computer graphics method $3 \mathrm{D}$ hip bone models from CT images are reconstructed [75]. Today numerical models can simulate different conditions in hip implants, for example [76], were it is shown investigation of the influence of the cup outer diameter on the contact mechanics and cement fixation of a hip implant with different wear parameters using finite element method. So, nowadays it is possible to use numerical modelling for preclinical test evaluations of the implant, but it should be noted that this models are becoming more accurate.

\section{Conclusions}

The aim of the hip implants design is mimicking the natural human hip design. The hip joint is one of the most important load-bearing, shock-resistant structures inside the human body during jumping, running and walking. It is known that a good understanding of stresses transmission on the joints and bones is very useful for preoperative planning and in postoperative rehabilitation. Short-term and longterm behaviour of total and partial hip prosthesis depends on optimal stress transmission within bone-implant compound.

Generally speaking, the human body is most vulnerable to joint fatigue, and applied biomaterials must be able to withstand a large number of working cycles. This is a very difficult condition for any synthetic biomaterial to fulfill. Long-term body response to materials used for implants presents a great problem as well, especially when waste created due to wear is not resorbable. Within the body, mechanical and chemical effects act simultaneously. During evaluation of biomaterial fatigue, a simulated environment with bodily fluids is used, along with built-in friction and electro-chemical mechanisms.

Table 2. Factors influencing hip implant integrity and life

\begin{tabular}{|c|c|}
\hline $\begin{array}{c}\text { Advantages of using FEM in hip implant } \\
\text { integrity analysis }\end{array}$ & $\begin{array}{c}\text { Factors influencing implant integrity and } \\
\text { life not possible to include by using FEM }\end{array}$ \\
\hline Applicable to complex geometries & Exact mechanical properties of bones \\
\hline Complex types of analysis & Effects of the environment (organism) \\
\hline Complex loads & $\begin{array}{c}\text { Possible complication after hip prosthetic } \\
\text { implantation }\end{array}$ \\
\hline $\begin{array}{c}\text { Models made of non-homogeneous } \\
\text { materials }\end{array}$ & $\begin{array}{c}\text { Allergies, necrosis and inflammatory } \\
\text { processes }\end{array}$ \\
\hline Contact surfaces models & Age, gender \\
\hline Structural integrity analysis & Activity level \\
\hline
\end{tabular}


In order to solve these and other problems, surgeons and bioengineers have defined project demands, as well as expected properties of suitable biomaterials. Project demands for joint prostheses are indeed very complex, since from the surgeon's standpoint, there are specific functional demands, and critical limitations due to currently available materials, and design limitations. Apart from a limited number of suitable materials, joint prostheses must also function in unfavorable environment and withstand extreme loads.

Arthroplasty problems are closely related to the properties of the material used. Depending on the region in which they should be installed, and the function that they should restore, the prerequisites for the selection of materials for the prosthesis are very different. Basically, every biomaterial must be compatible with the body (i.e. have negative tests for carcinogenicity, cytotoxicity, pyrogenicity etc.), must show a good chemical stability (corrosion resistance), which is extremely important, and must have the required mechanical properties (especially dynamic strength). Ideal metallic biomaterials for the femoral component should have a good fatigue characteristics, good strength characteristics, and high values of yield strength and tensile strength, and good corrosion resistance.

One of the key processes that accompany the product development process is a fundamental analysis of reliability, which is one of the main influencing factors on the implant integrity. Designers and manufacturers of medical devices must register their patents according to existing regulations and directives. Development of the medical device design is the first challenging step in the process of manufacturing of medical implants. Over time, the development of reliable and durable joint prostheses resulted in a significant improvement in the sustainable quality of work life in a large percentage of patients.

From the perspective of the price, reliable joint replacement prostheses with sustainable integrity are very cost-effective. The cost estimates may vary, though, depending on a number of factors such as: preoperative status, improvement opportunities, assessment of useful life, coexisting diseases.

In orthopedics, there always existed a significant interest in defining acting stresses and loads. However, mathematical tools which were available for stress analysis in classical mechanics were not suitable for calculations of extremely irregular structural characteristics of bones and implants. Thus the use of FEM represented a logical step due to its unique ability to determine the stress state of complex structures, loads and material behavior.

The final conclusions about the overall clinical performance of joint prostheses, and the best methods of fixation or designs, require long-term studies.

\section{Acknowledgments}

The work was supported by the Ministry of Education and Science of the Republic of Serbia, under the numbers TR 35040.

\section{Conflicts of interest}

State any potential conflicts of interest here or "The authors declare no conflict of interest".

\section{References}

1. Jeffrey N Katz (2006) Total joint replacement in osteoarthritis. Best Practice \& Research Clinical Rheumatology 20: 145-153.

2. Coomber R, Porteous M, Hubble MJ, Parker MJ (2016) Total hip replacement for hip fracture: Surgical techniques and concepts. Injury 47: 2060-2064. [Crossref]
3. Gard PJ, Fracs R. Iorio, Healy WL (2000) Hip replacement: Choosing an implant Operative Techniques in Orthopaedics 10: 94-101.

4. Roy Abraham, Arthur L. Malkani (2005) Instability after Total Hip Replacement. Seminars in Arthroplasty 16: 132-141.

5. Marco Viceconti, Giovanni Brusi, Alberto Pancanti, Luca Cristofolini (2006) Primary stability of an anatomical cementless hip stem: A statistical analysis. Journal of Biomechanics 39: 1169-1179.

6. Wang A, Essner A (2001) Three-body wear of UHMWPE acetabular cups by PMMA particles against CoCr. alumina and zirconia heads in a hip joint simulator 212-216.

7. Buford A, Goswami T (2004) Review of wear mechanisms in hip implants: Paper I General. Materials and Design 25: 385-393.

8. Slonaker M, Goswami T (2004) Review of wear mechanisms in hip implants: PaperIIceramics IG004712. Materials and Design 25: 395-405.

9. Amstutz HC, Le Duff MJ (2016) The Natural History of Osteoarthritis: What Happens to the Other Hip? Clin Orthop Relat Res 474: 1802-1809. [Crossref]

10. Bottai V, Dell'Osso G, Celli F, Bugelli G, Cazzella N, et al. (2015) Total hip replacement in osteoarthritis: the role of bone metabolism and its complications. Clin Cases Miner Bone Metab 12: 247-250. [Crossref]

11. Oh ES, Sieber FE, Leoutsakos JM, Inouye SK, Lee HB (2016) Sex Differences in Hip Fracture Surgery: Preoperative Risk Factors for Delirium and Postoperative Outcomes. $J$ Am Geriatr Soc 64: 1616-1621. [Crossref]

12. Dulic B (2003) Prelamin kuka (in serbian), Acta Clinica, Vol 3. br. 3, Klinicki centar Srbije, Beograd

13. Nasiri M, Luo Y (2016) Study of sex differences in the association between hip fracture risk and body parameters by DXA-based biomechanical modeling. Bone 90: 90-98. [Crossref]

14. Aurégan JC, Frison A, Bégué T, Hannouche D, Bosser C, et al. (2016) Contra-latera hip fracture in the elderly: are decreased body mass index and skin thickness predictive factors? Int Orthop [Crossref]

15. Lipovetzki Y, Zandman-Goddard G, Feldbrin Z, Shargorodsky M (2016) Elevated ferritin and circulating osteoprotegerin levels as independent predictors of hip fracture in postmenopausal women admitted for fragility fracture: time for new screening strategies? Immunol Res [Crossref]

16. Starup-Linde J, Frost M, Vestergaard P, et al. (2016) Epidemiology of Fractures in Diabetes. Calcif Tissue Int. [Crossref]

17. Boelch SP, Jordan MC, Meffert RH, Jansen H (2016) Comparison of open reduction and internal fixation and primary total hip replacement for osteoporotic acetabular fractures: a retrospective clinical study. Int Orthop. [Crossref]

18. George F. Chimento, Thomas P. Sculco (2001) Minimally Invasive Total Hip Arthroplasty. Operative Techniques in Orthopaedics 11: 270-273.

19. Cronin MD, Gofton W, Erwin L, Fitch DA, Chow J (2015) Early surgical and functional outcomes comparison of the supercapsular percutaneously-assisted total hip and traditional posterior surgical techniques for total hip arthroplasty: protocol for a randomized, controlled study. Ann Trans Med 3: 335. [Crossref]

20. González Della Valle A, Sharrock N, Barlow M, Caceres L, Go G, et al. (2016) The modern, hybrid total hip arthroplasty for primary osteoarthritis at the Hospital for Special Surgery. Bone Joint J. 98: 54-59. [Crossref]

21. Yuasa T, Maezawa K, Nozawa M, Kaneko K (2016) Cementless total hip arthroplasty for patients with rheumatoid arthritis: a more than 10-year follow-up. Eur J Orthop Surg Traumatol 26: 599-603. [Crossref]

22. Yuasa T, Maezawa K, Nozawa M, Kaneko K (2016) Midterm outcome of total hip arthroplasty for rapidly destructive coxarthrosis. J Orthop Surg (Hong Kong) 24: 2730. [Crossref]

23. Kalore NV, Cheppalli SP, Daner WE, Jiranek WA (2016) Acetabular Dysplasia in Middle-Aged Patients: Periacetabular Osteotomy or Total Hip Arthroplasty? J Arthroplasty 31: 1894-1898. [Crossref]

24. Sumayeh B. Abujaber, Adam R. Marmon, Federico Pozzi, James J. Rubano, Joseph A. Zeni Jr, (2015) Sit-To-Stand Biomechanics Before and After Total Hip Arthroplasty. $J$ Arthroplasty 30: 2027-2033. [Crossref]

25. Simpson DJ, Monk AP, Murray DW, Gill HS (2010) Biomechanics in orthopaedics: considerations of the hip and knee. Surgery (Oxford) 28: 478-482.

26. Richard van Arkel, Andrew Amis (2013) Basics of orthopaedic biomechanics. 


\section{Orthopaedics and Trauma 27: 67-75.}

27. Bjarnason JA, Reikeras O (2015) Changes of center of rotation and femoral offset in total hip arthroplasty. Ann Transl Med 3: 355. [Crossref]

28. Akiyama K, Nakata K, Kitada M, Yamamura M, Ohori T, et al. (2016) Changes in axial alignment of the ipsilateral hip and knee after total hip arthroplasty. Bone Joint $J$ 98-98B: 349-58. [Crossref]

29. Kaled Legweel, Aleksandar Sedmak, Katarina Colic, Miloš Miloševic, Nenad Mitrovic, et al. (2017) Experimental and numerical research of mechanical behaviour of titanium alloy hip implant, Technical Gazette ISSN 1330-3651 (print) ISSN1848-6339 (Online) 24:2017.

30. Alvarez-Vera M, Garcia-Duarte JH, Juarez-Hernandez A, Mercado-Solis RD, Castillo AG (2013) Failure analysis of $\mathrm{Co}-\mathrm{Cr}$ hip resurfacing prosthesis during solidification Case Studies in Engineering Failure Analysis 1: 1-5

31. Sedmak A, Colic K, Burzic Z, Tadic S (2010) Structural Integrity Assessment of Hip Implant Made of Cobalt-Chromium Multiphase Alloy. Structural Integrity and Life 10: $161-164$.

32. Lam LO, Stoffel K, Kop A, Swarts E (2008) Catastrophic failure of 4 cobalt-alloy Omnifit hip arthroplasty femoral components. Acta Orthop 79: 18-21. [Crossref]

33. Park JB (2000) "Hip Joint Prosthesis Fixation-Problems and Possible Solutions." The Biomedical Engineering Handbook: Second Edition, CRC Press LLC.

34. Kühn KD (2000) Bone Cements: Up-to-date comparison of physical and mechanical properties of commercial materials, Springer Verlag New York.

35. Schmalzried TP, Kwong LM, Jasty M, Sedlacek RC, Haire TC, et al, (1992) The Mechanism of loosening of cemented acetabular components in total hip arthroplasty, Clin Orthop Relat Res 274: 60-77. [Crossref]

36. McCormack BAO, Prendergast PJ (1996) An analysis of crack propagation paths at implant/bone-cement interfaces, J Biomech Eng 118: 579-585. [Crossref]

37. Yang DT, Zhang D, Dwayne D. Arola (2010) Fatigue of the bone/cement interface and loosening of total joint replacements. International Journal of Fatigue 32: 1639-1649.

38. Stea S, Visentin M, Granchi D, Ciapetti G, Donati ME. et al, (2000) Cytokines and Osteolysis Around Total Hip Prostheses, Cytokine 12: 1575-1579. [Crossref]

39. Ratner BD, Hoffman AS, Schoen FJ, Lemons JE (2004) Biomaterials Science - An Introduction to Materials in Medicine, Academic Press, San Diego.

40. Damien P. Byrne, Kevin J. Mulhall, Joseph F. Baker (2010) Anatomy \& Biomechanics of the Hip; The Open Sports Medicine Journal 51-57.

41. Gosheger G, Goetze C, Hardes J, Joosten U, Winkelmann W, et al. (2008) The influence of the alloy of megaprostheses on infection rate. J Arthroplasty 23: 916-920. [Crossref]

42. Schairer WW, Nwachukwu BU, Mayman DJ, Lyman S, Jerabek SA (2016) Preoperative Hip Injections Increase the Rate of Periprosthetic Infection After Total Hip Arthroplasty. J Arthroplasty. [Crossref]

43. Gittings DJ, Courtney PM, Ashley BS, Hesketh PJ, Donegan DJ (2016) Diagnosing Infection in Patients Undergoing Conversion of Prior Internal Fixation to Total Hip Arthroplasty, J Arthroplasty.

44. Müller RT, Heger I, Oldenburg M (1997) The mechanism of loosening in cemented hip prostheses determined from long-term results. Arch Orthop Trauma Surg 116: 41-45. [Crossref]

45. Marjan Bahraminasab (2012) et al., Aseptic loosening of femoral components - a review of current and future trends in materials used, Materials \& Design.

46. Parida P, Behera A, Mishra SC (2012) Classification of biomaterials used in medicine. Int J Adv Appl Sci 1: 31-35.

47. Colic K, Sedmak A, Gubeljak N, Burzic M, Petronic S, et al. (2012) Experimental analysis of fracture behavior of stainless steel used for biomedical applications, Integritet i vek konstrukcija (Structural Integrity and Lifre) 12: 59-63.

48. Hloch S, Monka P, Hvizdos P, Jakubeczyova D, Kozak DV. et al, (2014) Therma Manifestations and Nanoindentation of Bone Cements for Orthopaedic Surgery. Thermal Science 18: S251-S258

49. Merritt K, Brown SA (1996) Distribution of cobalt chromium wear and corrosion products and biologic reactions. Clin Orthop Relat Res: S233-243. [Crossref]

50. Manley MT, Sutton K (2008) Bearings of the future for total hip arthroplasty. $J$ Arthroplasty 23: 47-50. [Crossref]

51. Simões JA, Marques AT (2005) Design of a composite hip femoral prosthesis. Materials
\& Design 26: 391-401

52. Griza S (2009) Design aspects involved in a cemented THA stem failure case. Engineering Failure Analysis 16: 512-520.

53. Ruben RB, Fernandes PR, Folgado J (2012) On the optimal shape of hip implants. $J$ Biomech 45: 239-246. [Crossref]

54. Makarand G. Joshi, Suresh G. Advani, Freeman Miller, Michael H. Santare (2000) Analysis of a femoral hip prosthesis designed to reduce stress shielding. J Biomech 33 : 1655-1662. [Crossref]

55. Johanson PE, Antonsson M, Shareghi B, Kärrholm J (2016) Early Subsidence Predicts Failure of a Cemented Femoral Stem With Minor Design Changes. Clin Orthop Relat Res 474: 2221-2229. [Crossref]

56. Tsiampas DT, Pakos EE, Georgiadis GC, Xenakis TA (2016) Custom-made femora implants in total hip arthroplasty due to congenital disease of the hip: a review. Hip Int 26: 209-214. [Crossref]

57. Good V, Widding K, Hunter G, Heuer D (2005) Oxidized zirconium: a potentially longer lasting hip implant. Materials \& Design 26: 618-622.

58. Pompe W (2003) Functionally graded materials for biomedical applications. Materials Science and Engineering 362: 40-60.

59. Boudeau N, Liksonov D, Barriere T, Maslov L, Gelin JC (2012) Composite base on polyetheretherketone reinforced with carbon fibres, an alternative to conventional materials for femoral implant: Manufacturing process and resulting structural behaviour. Materials \& Design 40: 148-156.

60. Niinomi M, Nakai M, Hieda J (2012) Development of new metallic alloys for biomedical applications. Acta Biomater 8: 3888-3903. [Crossref]

61. Stuart Goodman (2014) Bearing Surfaces for Joint Replacement: New Materials or New Problems; Springer NewYork.

62. Kim YH, Park JW, Kim JS (2016) Ultrashort versus Conventional Anatomic Cementless Femoral Stems in the Same Patients Younger Than 55 Years. Clin Orthop Relat Res 474: 2008-2017. [Crossref]

63. Schmolders J, Amvrazis G, Pennekamp PH, Strauss AC, Friedrich MJ (2016) Thirteenyear follow-up of a cementless femoral stem and a threaded acetabular cup in patients younger than fifty years of age. Int Orthop [Crossref]

64. Swarup I, Marshall AC, Lee YY, Figgie MP (2016) Implant survival and patientreported outcomes after total hip arthroplasty in young patients with developmental dysplasia of the hip. Hip Int 26: 367-373. [Crossref]

65. Heller MO, Bergmann G, Kassi JP, Claes L, Haas NP, et al. (2005) Determination of muscle loading at the hip joint for use in pre-clinical testing. J Biomech 38: 1155-1163. [Crossref]

66. Heidi-Lynn Ploeg, Maja Bürgi, Urs P. Wyss (2009) Hip stem fatigue test prediction. International Journal of Fatigue 31: 894-905.

67. Hofstede SN, Gademan MG, Vliet Vlieland TP, Nelissen RG, Marang-van de Mheen PJ (2016) Preoperative predictors for outcomes after total hip replacement in patients with osteoarthritis: a systematic review. BMC Musculoskelet Disord [Crossref]

68. Katarina Colic, Aleksandar Sedmak, Aleksandar Grbovic, Uros Tatic, Simon Sedmak (2016) Finite Element Modeling of Hip Implant Static Loading. Procedia Engineering 149: $257-262$.

69. Katarina Colic, Aleksandar Sedmak, Aleksandar Grbovic, Meri Burzic, Sergej Hloch (2016) Numerical Simulation of Fatigue Crack Growth in Hip Implants 149: 229-235.

70. Senalp AZ, Kayabasi O, Kurtaran H (2007) Static, dynamic and fatigue behavior of newly designed stem shapes for hip prosthesis using finite element analysis. Materials and Design 28: 1577-1583.

71. David Bennett, Tarun Goswami (2008) Finite element analysis of hip stem designs Materials \& Design 29: 45-60.

72. Pyburn E, Goswami T (2004) Finite element analysis of femoral components paper III-hip joints. Materials and Design 25: 705-713.

73. Zohar Yosibasha, Alon Katza, Charles Milgromb (2013) Toward verified and validated FE simulations of a femur with a cemented hip prosthesis. Med Eng Phys 35: 978-987. [Crossref]

74. Raimondi MT, Santambrogio C, Pietrabissa R, Raffelini F, Molfetta L (2001) Improved mathematical model of the wear of the cup articular surface in hip joint prostheses and comparison with retrieved components. Proc Inst Mech Eng H 215: 377-391. [Crossref]

75. Liu Hao, Qian Hongbo, Zhao Jianning (2015) Automatic extraction of 3D anatomical 
Colic K (2016) The current approach to research and design of the artificial hip prosthesis: a review

feature curves of hip bone models reconstructed from CT images. Biomed Mater Eng 26: S1297-S1314. [Crossref]
76. Hua, Xijin (2015) The effect of cup outer sizes on the contact mechanics and cement fixation of cemented total hip replacements. Medical Engineering and Physics 37: $1008-1014$.

Copyright: (C2016 Colic K. This is an open-access article distributed under the terms of the Creative Commons Attribution License, which permits unrestricted use, distribution, and reproduction in any medium, provided the original author and source are credited. 